\title{
IMPLEMENTAÇÃO DE UM CURRÍCULO COM MUDANÇA RADICAL: SENTIMENTOS DE PRAZER E SOFRIMENTO*
}

[Implementation of a curriculum with radical change: feelings of pleasure and suffering]

[ Implementación de un currículo con cambio radical: sentimientos de placer y sufrimiento]

\author{
J úlia Trevisan M artins** \\ Maria Lúcia do Carmo C. Robazzi***
}

\begin{abstract}
RESUM 0: A presente pesquisa teve como objetivo verificar se as enfermeiras docentes vivenciam sentimentos de prazer e de sofrimento gerados no trabal ho, frenteà implementação de uma mudança curricular radical. Focaliza a compreensão a respeito da concepção que a enfermeira tem do exercício de sua função como docente no cotidiano de sua prática profissional. Trata-se de um estudo quantitativo, usando como método descrição exploratória, sendo que 0 instrumento utilizado para a coleta de dados foi uma escala tipo Likert composta de 39 questões distribuídas em três fatores: valorização, desgaste e reconhecimento que são indicadores de prazer e sofrimento. Fizeram parte desta pesquisa 30 enfermeiras docentes do curso de graduação em Enfermagem da U niversidade Estadual de L ondrina. Os resultados demonstraram que a maioria das enfermeiras docentes tem mais prazer do que sofrimento, pois, freqüentemente, sentem-se val orizadas, às vezes, sentemse reconhecidas e, às vezes, não se sentem desgastadas em suas atividades na implementação da mudança curricular radical. Esses dados nos revelam o quanto é importante as relações dos docentes com suas tarefas e com suas colegas, por ser neste espaço que se estabelecem os fatores que interagem diretamente nos sentimentos de prazer e sofrimento.
\end{abstract}

PALAVRAS-CHAVE: Satisfação no trabal ho; Enfermei ras; Docentes; Trabalho.

\section{INTRODUÇÃO}

Os métodos clássicos de organização do trabalho resultaram em sérias conseqüências para a saúde mental dos trabalhadores. Observa-se que nenhum deles trata a organização do trabal ho como um processo dinâmico, que

\footnotetext{
*Dissertação de M estrado defendida em dezembro de 2002. Escola de Enfermagem de Ribeirão Preto-USP.

**Docente mestre do Curso de Graduação em Enfermagem da Universidade Estadual de L ondrina - UEL.

***D ocente doutora da Escola de Enfermagem de Ribeirão Preto - USP.
}

envolve a subjetividade dos trabal hadores, cuja preocupação volta-se também para a saúde mental e não apenas para a saúde do corpo, entendida como saúde física.

$\mathrm{Na}$ perspectiva da psicodinâmica as relações humanas nas empresas são determinadas pela organização do trabal ho. Este pressuposto implica na compreensão de que, nos model os organizacionais os aspectos subjetivos do trabal ho são relevantes.

A psicodinâmica do trabal ho configura-se como a análise dos processos psíqui cos mobilizados pelo confronto do sujeito com a realidade do trabalho. Compreende a ligação entre homem e trabal ho como recurso de produção de significações psíquicas e de construção de relações sociais, em que há uma mediação entre o psíquico e o social, o particular e o col etiv ${ }^{(1)}$. D esta forma, fazer uma incursão a respeito do processo e a organização do trabalho permite esclarecer que o trabalho por si só não é nocivo e perigoso, ao contrário 0 que 0 torna perigoso é a forma como ele é organizado pelo homem ${ }^{(2)}$.

0 trabal ho do docente é tido como uma atividade, em que este profissional possui certa autonomia para gerenciar a sua forma de organização. Entretanto, os procedimentos adotados para efetivá-la desconsideram as questões da subjetividade dos docentes, individual e/ou coletivamente, podendo assim desencadear sofrimento no trabalho.

A busca do prazer no trabalho e a fuga do sofrimento são um dos desejos do trabalhador, em oposição às exigências feitas na organização do trabalho. Desse modo, uma condição para se obter o prazer no trabalho ocorre quando a organização torna-se flexível, permitindo ao trabalhador uma maneira de empregar as aptidões psicomotoras, psicosensoriais e psíquicas ${ }^{(3)}$.

A tual mente 0 curso de graduação em Enfermagem da Universidade Estadual de Londrina, implementa uma mudança curricular que muda radicalmente a organização do processo de trabalho das enfermeiras docentes, bem como, traz um novo paradigma de concepção de ensino aprendizagem. Percebe-se que essa situação ímpar vem provocando sentimentos diversos, no comportamento, nas 
atitudes e nas atividades no cotidiano acadêmico dessas professoras. Para muitas tem significado um momento de criação, de al egria pelo crescimento e realização pessoal. Para outras, tem gerado sentimento de sofrimento pela perda do sentido do trabalho, desgaste físico, mental e o não reconhecimento e valorização do esforço que estão realizando.

A ssim, com o objetivo de investigarmos se as enfermei ras docentes vivenciaram sentimentos de prazer $e$ sofrimento gerados pelo trabalho, frente à implementação de uma mudança curricular radical, procuramos compreender as contradições por elas vivenciadas, por intermédio de questões que envolvem a valorização, 0 desgaste e o reconhecimento, como fatores que predominam, em maior ou menor escala no processo psicodinâmico do trabalho que constituem os sentimentos de prazer e sofrimento no cotidiano acadêmico. Conforme $M$ endes ${ }^{(4)}$,

valorização é o sentimento de que 0 trabalho tem sentido e valor por si mesmo, sendo importante e significativo para a organização e a sociedade. Desgaste, significa a sensação de cansaço, desânimo e descontentamento. Reconhecimento é o sentimento de ser aceito e admirado no trabalho e ter liberdade para expressar sua individualidade ${ }^{(0.135)}$.

N osso estudo está apoiado no referencial teórico de Dejours ${ }^{(5)}$, a partir da perspectiva da psicodinâmica, pois oferece-nos subsídi os para anal isarmos aspectos subjetivos que influenciam e afetam as relações dos docentes no cotidiano acadêmico, bem como, permite-nos investigar a relação direta destes com o trabal ho.

\subsection{OBJETIVO}

Verificar se as enfermeiras docentes vivenciam sentimentos de prazer e sofrimento gerados no trabalho frenteà implementação de uma mudança curricular radical.

\section{METODOLOGIA}

Este estudo foi desenvolvido dentro da abordagem da pesquisa quantitativa, utilizando o método descritivo exploratório. 0 instrumento utilizado para a col eta dos dados foi a Escala de Indicadores de Prazer e Sofrimento no Trabal ho, que foi val idada e aplicada por $\mathrm{M}$ endes ${ }^{(4)} \mathrm{em}$ sua tese de doutoramento e teve como base a aplicação da escala de Likert. 0 instrumento foi composto de 39 afirmativas, distribuídas em três fatores: valorização, desgaste e reconhecimento (A nexo I). As afirmações foram respondidas em uma escala que possuía cinco intervalos pontuados de 1 a 5, correspondendo: 1 a afirmativa nunca; 2 a raramente; 3 a às vezes; 4 a freqüentemente; e 5 a sempre. Como qual quer intervalo de classe possui seu ponto médio, definido como valor mais central do mesmo, utilizamos a seguinte fórmula para determiná-la ${ }^{(6)}$ : $\frac{\text { limite inferior }+ \text { limite superior }}{2}=\frac{1+5}{2}=3,0$

0 que corrobora o cálculo da média levando em conta as ponderações:

$\frac{\text { Pontuações }}{\mathrm{N}=\mathrm{n}^{\circ} \text { de termos }}=\frac{1+2+3+4+5}{5}=\frac{15}{5}=3,0$

A investigação foi realizada na cidade de $L$ ondrina, Estado do Paraná, com 30 enfermeiras docentes do curso de graduação em Enfermagem da U niversidade Estadual de L ondrina. No seu desenvolvimento foram consideradas as Diretrizes e Normas Regulamentadoras da Pesquisa Envolvendo Seres Humanos 196/96 com obtenção de parecer do Comitê de Ética e o Consentimento Livre e Esclarecido dos participantes, após as informações fornecidas pela pesquisadora sobre o objetivo da pesquisa, sendo-Ihes assegurado 0 anonimato ${ }^{(7)}$.

A coleta de dados foi real izada nos meses de jul ho e setembro do ano de 2002 e adotamos como critério para inclusão na pesquisa: ser docente em caráter ef etivo no departamento; ter participado da implementação do currículo com mudança radical e ter consentido em participar da pesquisa.

\section{RESULTADOSE DISCUSSÃO}

A seguir, apresentamos um quadro geral com os resultados encontrados na presente investigação.

Quadro 1 - Distribuição das freqüências das médias referentes aos fatores valorização, desgaste e reconhecimento. L ondrina-PR, 2002 


\begin{tabular}{|c|c|}
\hline QUESTÕES & Média \\
\hline Fator $>$ & VALORIZAÇÃO \\
\hline 01 Meu trabalho é importante para o curso de Enfermagem & 4,43 \\
\hline 04 Quando executo minhas tarefas realizo-me profissionalmente & 3,77 \\
\hline 07 Meu trabalho tem finalidade & 4,27 \\
\hline 10 Utilizo minha criatividade no desempenho de minhas tarefas & 3,93 \\
\hline 13 Sinto-me útil no meu trabalho & 4,07 \\
\hline 16 Consigo adaptar meu trabalho às minhas necessidades & 2,93 \\
\hline 19 Minhas tarefas são significativas para mim & 4,03 \\
\hline 22 Minhas tarefas não são banais & 4,30 \\
\hline 27 Sinto orgulho do trabalho que realizo & 3,70 \\
\hline 30 Sinto-me produtiva no meu trabalho & 3,67 \\
\hline 33 Minhas tarefas exigem conhecimentos específicos & 4,40 \\
\hline 35 Identifico-me com minhas tarefas & 3,53 \\
\hline 37 Meu trabalho contribui para o desenvolvimento da sociedade & 4,30 \\
\hline 38 Tenho disposição para realizar minhas tarefas & 3,90 \\
\hline 39 Minhas tarefas são significativas para as pessoas em geral & 3,50 \\
\hline Média Geral & 3,90 \\
\hline Fator $>$ & DESGASTE \\
\hline 02 Meu trabalho é cansativo & 3,53 \\
\hline 05 Sinto-me injustiçado pelo sistema de promoção da organização & 2,77 \\
\hline 08 Meu trabalho é desgastante & 3,67 \\
\hline 11 Sinto satisfação no meu trabalho & 3,63 \\
\hline 14 Tenho frustrações com meu trabalho & 3,27 \\
\hline 17 Permaneço neste emprego por falta de oportunidade no mercado & 1,80 \\
\hline 20 Minhas tarefas são desagradáveis & 2,60 \\
\hline 23 Revolta-me a submissão da coordenação do colegiado às ordens superiores & 2,70 \\
\hline 25 Sinto-me sobrecarregada no meu trabalho & 4,03 \\
\hline 28 A repetitividade das minhas tarefas me incomoda & 2,57 \\
\hline 31 Sinto desânimo no meu trabalho & 3,00 \\
\hline 34 Meu trabalho me causa sofrimento & 3,10 \\
\hline 36 Fico revoltada quando tenho que submeter meu trabalho às decisões políticas & 3,80 \\
\hline Média Geral & 3,10 \\
\hline Fator $>$ & RECONHECIMENTO \\
\hline 03 Sinto o reconhecimento das minhas colegas pelo trabalho que realizo & 3,13 \\
\hline 06 Tenho autonomia no desempenho das minhas tarefas & 3,03 \\
\hline 09 Tenho liberdade para dizer o que penso sobre meu trabalho & 3,27 \\
\hline 12 No meu trabalho uso meu estilo pessoal & 3,77 \\
\hline 15 Sinto minhas colegas docentes solidárias comigo & 3,40 \\
\hline $18 \mathrm{O}$ tipo de trabalho que faço é admirado pelos outros & 2,93 \\
\hline 21 Tenho liberdade para organizar meu trabalho da forma que quero & 2,60 \\
\hline 24 No meu trabalho posso ser eu mesma & 3,37 \\
\hline 26 No meu trabalho participo desde o planejamento até a execução das tarefas & 3,47 \\
\hline 29 Gosto de conviver com minhas colegas docentes no trabalho & 3,87 \\
\hline 32 Sinto o reconhecimento da coordenação do colegiado pelo trabalho que realizo & 2,77 \\
\hline Média Geral & 3,20 \\
\hline
\end{tabular}


Podemos observar, pelo quadro anterior e levandose em conta a média estabelecida 3,0 que o maior índice nas questões do fator valorização, foi determinado pela questão " $M$ eu trabalho é importante para o curso de Enfermagem", que apresentou uma média de 4,43. Já 0 menor índice foi o da questão 16 "Consigo adaptar meu trabal ho às minhas necessidades", que obteve uma média de 2,93. A média geral obtida no fator valorização foi 3,9, 0 que nos leva a inferir que a maioria das entrevistadas, freqüentemente, sente-se val orizada em suas atividades.

Com relação às questões do fator reconhecimento o maior índice foi determinado pela questão 29 "Gosto de conviver com minhas colegas docentes no trabalho", que apresentou uma média de 3,87. Já o menor índice foi obtido na questão 21 "Tenho liberdade para organizar meu trabal ho da forma que quero", que de acordo com a escala obteve uma média de 2,60. A média geral obtida no fator reconhecimento foi 3,2, o que nos leva a inferir que a maioria das entrevistadas, às vezes, sente-se reconhecida em suas atividades.

Com relação às questões do fator desgaste o maior índice foi determinado pela questão 25 "Sinto-me sobrecarregada no meu trabalho", que apresentou uma média de 4,03. Já o menor índice foi da questão 17 "Permaneço neste emprego por falta de oportunidade no mercado", que obteve uma média de 1,80. A média geral obtida no fator desgaste foi de 3,1, o que nos leva a inferir que a maioria das entrevistadas, às vezes, não se sente desgastada em suas atividades.

Os resultados evidenciaram que a maioria das enfermeiras docentes sentem mais prazer do que sofrimento no trabalho, haja vista que freqüentemente, sentem-se valorizadas em suas atividades, às vezes, sentem-se reconhecidas em suas atividades e às vezes, não se sentem desgastadas.

0 sentimento de val orização não acontece somente pelas manifestações positivas das colegas, mas especialmente pelo prazer que a execução do trabal ho gera para aquele que o realiza e também para a profissão. Esta situação encontra respaldo em citação de $M$ endes ${ }^{(4)}$, ao mencionar que o trabalho é real ização, é identidade, e que para produzir algo, o trabal hador deve se sentir estruturado como pessoa e para isso tem que ser valorizado e reconhecido pelo que faz. Desta forma, atende às necessidades que variam da sobrevivência até a autorealização.

Para Dejours ${ }^{(8)}$ todo trabal ho é geralmente fruto de esforços que exigem concentração, gasto de energia e investimento pessoal. Portanto, nada mais justo que 0 trabal hador seja val orizado e reconhecido ao desempenhar suas atividades, caso isso não seja percebido pelos outros pode então ser desencadeado o sentimento de sofrimento ao invés de sentimento de prazer. Q uando o trabalho provoca um desgaste excessivo, mas os esforços despendidos são reconhecidos e val orizados, o trabal hador compreende que não foi em vão o desgaste, o investimento, e passa a acreditar que contribui para a organização bem como para si próprio.

0 trabalho é uma expressão de liberdade, de humanidade e, portanto, origem de muitas realizações, quando ele é visto somente como amostra da produtividade, e de benefício para a organização, o trabal hador se degrada, por não se satisfazer, passando a ter um desgaste contínuo com possibilidades de ter mais sofrimento do que prazer em suas atividades. D esse modo, uma condi ção para se obter prazer no trabalho é tornar a organização o mais flexível, permitindo ao trabalhador uma forma de empregar suas aptidões ${ }^{(3)}$.

\section{CONCLUSÃO E RECOMENDAÇÕES}

Os resultados desta pesquisa demonstraram que apesar da implementação curricular ter provocado diferentes formas de organização do trabal ho das enfermeiras docentes, está trazendo mais prazer do que sofrimento, porque tem propiciado ao grupo uma flexibilidade no processo de trabalho, em que a criatividade e a iniciativa são constantes. É um trabalho no qual o desafio tem sido incessante, porém é também um espaço favorável para descobertas e criações socialmente úteis.

Diante da experiência adquirida com a presente pesquisa, as interpretações ef etuadas, as reflexões realizadas e os anos de vivência profissional, permitiram-nos levantar algumas recomendações:

- A mudança radical de um currículo deve ser amplamente discutida no e com o grupo de docentes que estão implementando.

- A implementação curricular aponta um caminho, uma direção, deve ser plantada com a ajuda, a participação e as sugestões de todos, para que possa enraizar e enfrentar os problemas de qual quer ordem que possam surgir. Dessa forma deve, sobretudo, revelar, valorizar, reconhecer e respeitar as contribuições dos seus protagonistas.

- Toda e qualquer proposta, para ter bons frutos, precisa considerar tudo e todos, ou seja, o que existe, o que foi realizado e por quem foi realizado. A história não pode simplesmente ser apagada, pois é nela que se encontram as bases de qualquer futuro.

- E em face do novo, das suas formas de implementação e de suas conseqüências, faz-se necessário que docentes tenham apoio multidisciplinar de pedagogos, educadores, administradores e psicólogos, al ém de outros, para 0 enfrentamento de questões que já surgiram, estão surgindo e que venham a surgir, especialmente, de ordem pedagógica e emocional.

ABSTRACT: The present research aimed to verify if nursing teachers experience feelings of pleasure and suffering in their work due to the implementation of a radical curricular change. It focuses on the understanding of nurses' 
conception about their teaching role in their daily professional practice. It's a quantitative study, using the exploratory descriptive method, and a "Likert" type scale entailing ${ }^{(39)}$ questions distributed in three factors: valueing, stress and recognition, indicators of pleasure and suffering, as the instrument. Thirty ${ }^{\left({ }^{30}\right)}$ nursing teachers of the N ursing graduation course of The State University of L ondrina participated in this research. The results demonstrated that most nursing teachers feel more pleasure than suffering, because, they are often valued, sometimes, they are recognized and sometimes, they do not get stressed by their activities in the implementation of a radical curricular change. Those data reveal how important the relationships of the educational nurses with theirs tasks and colleagues are, once it is in this setting that the factors that directly interact in the feelings of pleasure and suffering are brought on.

KEY W O RDS: Pleasure; Suffering; N urse; Teacher; Work.

RESUM EN: Esta investigación ha tenido como objetivo verificar si las enfermeras docentes viven sentimientos de placer y sufrimiento generados en el trabajo a la implementación de cambio curricular radical. Es focal izada la comprensión acerca de la concepción que la enfermera tiene del ejercicio de su función como docente en el cotidiano de su práctica profesional. Este es un estudio cuantitativo que utiliza como método la descripción exploratoria, siendo usado como instrumento para recoger los datos una escala del tipo L ikert, compuesta de cuestiones distribuidas en tres factores: valoración, desgaste y reconocimiento, los cuales son indicadores de placer y sufrimiento. Hicieron parte de esta investigación enfermeras docentes del curso de graduación en Enfermería de la Universidade Estadual de Londrina. Los resultados demostraron que la mayoría de las enfermeras docentes tiene más placer que sufrimiento, pues, frecuentemente, se sienten desgastadas en sus actividades en la implementación del cambio curricular radical. Los datos revelan cómo son importantes las relaciones de los docentes con sus tareas y sus colegas, pues en ese espacio se establecen los factores que interaccionan directamente en los sentimientos de placer y sufrimiento.

PALABRAS CLAVE: Placer; Sufrimiento; Enfermera; Docente; Trabajo.

\section{REFERÊNCIAS}

1. M endes A M B , A brahão JI. Organização do trabalho e vivências de prazer e sofrimento do trabalhador: abordagem psicodinâmica. Rev Psicol Teoria Pesq 1996; 12:179-84.

2. Cohn A, M arsiglia RG. Processo e organização do trabalho. In: Rocha EL, Rigotto RM , B uschinelli JTP. Isto é trabal ho de gente? Vida, doença e trabalho no Brasil. São Paulo: Vozes; 1994. Cap. 4, p. 56-108.
3. Dejours C. A carga psíquica do trabal ho. In: Dejours C, A bdoucheli E, $J$ ayet C. Psicodinâmica do trabal ho: contribuições da escola dejourina à análise da relação prazer, sofrimento e trabalho. São Paulo: A tlas, 1994. p. 45-65.

4. M endes A M B. Valores e prazer - sofrimento no contexto organizacional. [tese]. B rasília: Instituto de Psicologia da Universidade de Brasília, Universidade Nacional de Brasília, ; 1999.

5. Dejours C. A loucura do trabalho: estudo de psicopatologia do trabaIho. 3. ed. São Paulo: Cortez-O boré; 1988. 163 p.

6. Ribeiro GC. Estudo de discrepância na aprendizagem. [dissertação]. Porto A legre: Pontifícia U niversidade Católica do Rio Grande do Sul; 1986.

7. B rasil. Resolução $n$. 196. Sobre perquisas envolvendo seres humanos. Diário Oficial da República federativa do Brasil, Brasília, 10 de out. 1996.

8. Dejours C. A B analização da injustiça social. Rio de Janeiro: Editora FGV, 2000. 
ANEXO I

INSTRUMENTO

LEIA AS FRASES ABAIXO, ANALISANDO CADA UMA DE ACORDO COM O QUE VOCÊ SENTE NO DIA-A-DIA DO TRABALHO COM A IM PLEMENTAÇÃO DA MUDANÇA CURRICULAR RADICAL NO ANO 2000 (CURRÍCULO INTEGRADO). MARQUE, UTILIZANDO A ESCALA ABAIXO, O NÚMERO QUE MELHOR CORRESPONDE À SUA AVALIAÇÃO.

\begin{tabular}{|c|c|c|c|c|}
\hline 1 & 2 & 3 & 4 & 5 \\
Nunca & Raramente & Às vezes & Freqüentemente & Sempre \\
\hline
\end{tabular}

Na implementação do Currículo I ntegrado...

\begin{tabular}{|c|c|c|c|c|c|}
\hline 1. Meu trabalho é importante para o curso de Enfermagem & 1 & 2 & 3 & 4 & 5 \\
\hline 2. Meu trabalho é cansativo & 1 & 2 & 3 & 4 & 5 \\
\hline 3. Sinto o reconhecimento das minhas colegas pelo trabalho que realizo & 1 & 2 & 3 & 4 & 5 \\
\hline 4. Quando executo minhas tarefas realizo-me profissionalmente & 1 & 2 & 3 & 4 & 5 \\
\hline 5. Sinto-me injustiçado pelo sistema de promoção da organização & 1 & 2 & 3 & 4 & 5 \\
\hline 6. Tenho autonomia no desempenho das minhas tarefas & 1 & 2 & 3 & 4 & 5 \\
\hline 7. Meu trabalho tem finalidade & 1 & 2 & 3 & 4 & 5 \\
\hline 8. Meu trabalho é desgastante & 1 & 2 & 3 & 4 & 5 \\
\hline 9. Tenho liberdade para dizer o que penso sobre meu trabalho & 1 & 2 & 3 & 4 & 5 \\
\hline 10. Utilizo minha criatividade no desempenho de minhas tarefas & 1 & 2 & 3 & 4 & 5 \\
\hline 11. Sinto satisfação no meu trabalho & 1 & 2 & 3 & 4 & 5 \\
\hline 12. No meu trabalho uso meu estilo pessoal & 1 & 2 & 3 & 4 & 5 \\
\hline 13. Sinto-me útil no meu trabalho & 1 & 2 & 3 & 4 & 5 \\
\hline 14. Tenho frustrações com meu trabalho & 1 & 2 & 3 & 4 & 5 \\
\hline 15. Sinto minhas colegas docentes solidárias comigo & 1 & 2 & 3 & 4 & 5 \\
\hline 16. Consigo adaptar meu trabalho às minhas necessidades & 1 & 2 & 3 & 4 & 5 \\
\hline 17. Permaneço neste emprego por falta de oportunidade no mercado & 1 & 2 & 3 & 4 & 5 \\
\hline 18. O tipo de trabalho que faço é admirado pelos outros & 1 & 2 & 3 & 4 & 5 \\
\hline 19. Minhas tarefas são significativas para mim & 1 & 2 & 3 & 4 & 5 \\
\hline 20. Minhas tarefas são desagradáveis & 1 & 2 & 3 & 4 & 5 \\
\hline
\end{tabular}

Continua 


\begin{tabular}{|c|c|c|c|c|c|}
\hline 21. Tenho liberdade para organizar meu trabalho da forma que quero & 1 & 2 & 3 & 4 & 5 \\
\hline 22. Minhas tarefas não são banais & 1 & 2 & 3 & 4 & 5 \\
\hline 23. Revolta-me a submissão da coordenação do colegiado às ordens superiores & 1 & 2 & 3 & 4 & 5 \\
\hline 24. No meu trabalho posso ser eu mesma & 1 & 2 & 3 & 4 & 5 \\
\hline 25. Sinto-me sobrecarregada no meu trabalho & 1 & 2 & 3 & 4 & 5 \\
\hline 26. No meu trabalho participo desde o planejamento até a execução das tarefas & 1 & 2 & 3 & 4 & 5 \\
\hline 27. Sinto orgulho do trabalho que realizo & 1 & 2 & 3 & 4 & 5 \\
\hline 28. A repetitividade das minhas tarefas me incomoda & 1 & 2 & 3 & 4 & 5 \\
\hline 29. Gosto de conviver com minhas colegas docentes no trabalho & 1 & 2 & 3 & 4 & 5 \\
\hline 30. Sinto-me produtiva no meu trabalho & 1 & 2 & 3 & 4 & 5 \\
\hline 31. Sinto desânimo no meu trabalho & 1 & 2 & 3 & 4 & 5 \\
\hline 32. Sinto o reconhecimento da coordenação do colegiado pelo trabalho que realizo & 1 & 2 & 3 & 4 & 5 \\
\hline 33. Minhas tarefas exigem conhecimentos específicos & 1 & 2 & 3 & 4 & 5 \\
\hline 34. Meu trabalho me causa sofrimento & 1 & 2 & 3 & 4 & 5 \\
\hline 35. Identifico-me com minhas tarefas & 1 & 2 & 3 & 4 & 5 \\
\hline 36. Fico revoltada quando tenho que submeter meu trabalho às decisões políticas & 1 & 2 & 3 & 4 & 5 \\
\hline 37. Meu trabalho contribui para o desenvolvimento da sociedade & 1 & 2 & 3 & 4 & 5 \\
\hline 38. Tenho disposição para realizar minhas tarefas & 1 & 2 & 3 & 4 & 5 \\
\hline 39. Minhas tarefas são significativas para as pessoas em geral & 1 & 2 & 3 & 4 & 5 \\
\hline
\end{tabular}

